\title{
Research on "Praxis-oriented" Curriculum of Pre-school Education Major
}

\author{
Ya Li
}

\author{
Bao Shan University, Baoshan, Yunnan, 678000, China
}

Keywords: Pre-school Education Major; "praxis-oriented"; curriculum setting; research.

\begin{abstract}
With the reform and change of the social system, the education system in China is constantly changing towards the perfect development direction. The professional quality can decide teachers' competence in education level from the root, while the curriculum they receive plays a decisive role in the formation of the professional quality. Based on the practice concept of education curriculum for teachers and a great deal of investigations into the practical implementation of curriculum for the major of Education, it can be seen that there are many problems in the implementation process of education curriculum for students majoring in Pre-school Education of colleges in China. For examples, the mode of curriculum organization is mainly based on imparting; the way of curriculum evaluation is single; the content emphasizes theoretical knowledge; and curriculum objectives ignore the cultivation of students' ability of practice or reflection. This paper makes a detailed study on the "praxis-oriented" curriculum of Pre-school Education, hoping to provide reference for future professional research.
\end{abstract}

\section{Introduction}

With the development of China's education system, the Pre-school Education Major has been commonly set up in colleges and universities in China, which has made the professional level and comprehensive quality of Chinese college teachers change from quantity improvement to quality improvement. However, there are still a lot of problems in the process of actual implementation. In view of these problems, colleges and universities should attach importance to the cultivation of students' ability of practice and reflection in the course experience and comprehensive contents should be highlighted in curriculum, so as to promote the basic quality of students to be unified in practice. In addition, various organization modes as well as a series of effective measures like multiple evaluation forms based on curriculum objectives should be used in teaching, which can not only promote the training mode reform of teacher education, but also promote the adjustment and innovation of teacher training mode in normal colleges and universities.

\section{Problems Existing in the Organization and Implementation of the Education Curriculum for Students Majoring in Pre-School Education in Colleges and Universities}

1. Curriculum objectives ignore the cultivation of students' ability of practice or reflection

It can be found from the great deal of actual investigation that, although the Pre-school Education Major in most colleges and universities in China has professional theoretical courses and practical courses, the proportion of the two is not reasonable -- the time of theoretical courses occupies nearly $80 \%$ of the curriculum. The theoretical courses cover teacher education, professional compulsory courses, professional elective courses, sports, computer, English, etc., but the practical courses just mainly include the teaching methods. This reflects the excessive attention to the mastery of theoretical knowledge and neglect of the ability in practice [1].At the same time, most of practical courses are carried out in the classroom in students' own school, so that the practical courses implemented are non-formal ones. For students enrolled in normal colleges, they generally spend three fourths of their school years in their own school, with few interactions with other colleges and educational institutions. They have few opportunities for learning and experiencing in other colleges and universities before they are senior students, so that the theoretical knowledge they have learned 
cannot be fully realized in practice. That students' knowledge and emotions cannot be combined with each other makes them unable to feel and discover the actual situation and existing problems in college education, and thereby they cannot think and have no ideas about related problems.

2. The curriculum content emphasizes theoretical knowledge

Promoted by new curriculum reform, the degree of education reform in China is gradually expanding and the corresponding curriculum content has also become more abundant. However, there are still many problems in the actual education and teaching. First, theoretical specialized courses occupy high proportion. At present, theoretical courses in most colleges and universities in China account for $80 \%$ of the total curriculum. At the same time, the fierce competition in the employment market makes the four-year schooling of normal college students be severely shortened to three and a half years or even three years, which leads to the increasing serious problems between the theory and practice of education. Secondly, there is a serious lack of attention to the curriculum arrangement for educational practice. For normal college interns, the necessary practical ability is indispensable, because only a certain amount of practical knowledge can lay a solid foundation for them to become the excellent teacher [2].However, in practice, most normal colleges arrange the students' internship in the seventh or eighth semester due to the heavy teaching tasks and limited teaching time. In the four school years, the overall time for educational practice courses is no more than one month or even less.

3. The mode of curriculum organization is mainly based on imparting

The teaching mode in most of China's normal colleges today has been significantly improved in the promotion of the new curriculum reform, but it still dominated by teachers' paraphrasing and teaching because of the deeply ingrained effect of the traditional education mode. It is difficult to see the students actively cooperate with the teacher in the classroom. The homogenous content in teaching activities cannot realize the purpose of diversified teaching and has no practical significance. That students' enthusiasm for participation cannot be aroused results in that they are unable to improve their ability to solve problems in practice, learn theoretical and practical knowledge independently and communicate with others [3]. At the same time, the teachers in normal colleges often do not comprehensively develop and fully integrate the theoretical knowledge into practical knowledge, and thus they are not able to correctly guide the students to pay more attention to practical problems, resulting in the two being seriously separated from the reality. Moreover, many students in normal colleges do not understand the development and changes of first-line education, so that they cannot discover and study the real problems.

4. The way of curriculum evaluation is single

As the process to analyze and judge the value of curriculum, curriculum evaluation is mainly for the main part of the curriculum and the characteristics of courses, which is not only the scientific evaluation and assessment of the impact of course changes on the number and extent but also the comprehensive evaluation of whether the objectives of curriculum have been completed or not [4].For the objective of Pre-school Education Major, in addition to promoting the students' all-round development of virtue, intelligence, physical conditions, mind status and community service, it is also an important aspect to perfect teachers' professional accomplishment, educational consciousness, design ability of practical class and the capacity of self-evaluation and self-perfection. However, a great deal of practical investigations showed that the Pre-school Education Major in most colleges and universities does not focus on cultivation of these aspects. Therefore, the evaluation can only assess students' understanding and mastery of knowledge. It is a summative assessment which cannot understand the true cognition and perception of normal college students of higher education.

\section{Enlightenment of the "Praxis-Oriented" Idea to the Organization and Implementation of the Education Curriculum for Students Majoring in Pre-School Education in Colleges and Universities}

1. Attaching importance to the cultivation of students' ability of practice and reflection in the course experience 
The praxis-oriented education mode mainly takes the development of the students as the main purpose to train them into all-round talents. Teachers should reasonably integrate the orientation of practice in the classroom education. In other words, teachers should more highlight practical courses in their teaching to enable students to focus on the real problems, feel the significance of education in the actual operation, and thus enhance their teaching level. In practice, the praxis-oriented education mode can deepen the knowledge, education, ability and belief of students in a certain environment and achieve their professional and independent development; and this process will change the long-term development of teachers from the traditional cultivation after being employed to the pre-service training [5].Teachers' professional quality is basically a general term for teachers' knowledge and professional ability formed by positive factors such as persistence, self-confidence and importance of their profession. It is the teacher's belief that the teacher has developed slowly after pre-service education and practical education. The professional quality of the teacher is the core proposition in the current educational mode in China.

2. Promoting the basic quality of students to be unified in practice through comprehensive curriculum contents

The comprehensiveness of teaching contents mainly refers to the organic combination of professional theoretical knowledge and practical educational practice. For example, in order to make students able to apply the theoretical knowledge in practice well, normal colleges should disperse the praxis-oriented education into at least four semesters and the degree of difficulty can be increase from low grade to high grade. The first praxis-oriented education activity can be carried out in the second semester of the first school year, with the duration of seven days. The purpose is to enable students to have a perceptual cognition of the specific contents of coming praxis-oriented education. The second and third praxis-oriented education internships lasting one week to weeks can be carried out in the second and third school years, aiming at enabling students to experience the characteristics of teachers' work and feel of debut. The fourth and fifth praxis-oriented education activities are expected to take place in the seventh and eighth semesters. It is needed to ensure that students' internship time is over twelve weeks and arrange outstanding professional teachers to instruct them [6].Alternation of theory and practice enables students to understand the theoretical knowledge about pre-school education, deeply feel praxis-oriented education and gradually become familiar with the teaching norms and procedures of university teachers, so that they can give full play to the role of Pre-school Education Major.

3. Adopting various organization modes to allow students apply what they have learned

Teaching environment is very important for the selection of content and mode of pre-school education, and thus it is necessary to carry out thematic presentation, theme discussion, cooperative communication, case teaching and other modes on the basis of formal professors. Colleges and universities should focus on solving problems and highlight the pertinence, practicality and efficiency; special attention should be given to case teaching and situational teaching to closely link education with the actual situation [7].Firstly, theoretical study, as the basis of practice, points out the specific direction for the development of practical learning. Secondly, actual experience, as a kind of perceptual experience, can effectively supplement the educational experience that normal students do not have. Thirdly, the experience summary can combine and review the learning effect of the first two periods.

4. Employing multiple evaluation forms based on curriculum objectives

Applied talent is the main training direction of pre-school education, which must be based on practice. It should not only attach importance to the process, but also pay attention to the evaluation. On the one hand, the educational concept of normal college students must be active and positive. The role of diversification should be reasonably quoted in the evaluation mechanism in order to realize the training of students' ability, attitude and professionalism. On the other hand, the importance of the ability inspection should be highlighted reasonably in the theoretical assessment. The evaluation mechanism should include field operation, case study, curriculum arrangement, classroom simulation, effect demonstration, achievement display, etc., which gives priority to the teacher's evaluation while being supplemented by students' self-assessment and peer evaluation [8]. 


\section{Conclusion}

It can be seen from the research on the "praxis-oriented" Pre-school Education Major that, there are still many problems in the application of "praxis-oriented" preschool education of Chinese colleges, such as the organization dominated by teaching, single way of curriculum evaluation, the emphasis on theoretical knowledge and training objectives ignoring students' reflective ability. A series of countermeasures should be adopted to deal with these problems. .For examples, the course experience should lay stress on the cultivation of students' reflection ability in practice; integrated contents are needed to promote the unification of students' basic quality in practice; a variety of ways should be adopted to help students apply what they have learned; and multiple evaluation forms should be employed based on the curriculum objectives, so as to ensure the more professional and standardized implementation of "praxis-oriented” teaching for preschool education in China.

\section{Acknowledgments}

Funded project: the science research fund project of Yunnan Provincial Education Department Practical Teaching System Construction of Pre-school Education Major in Local Colleges and Universities -- Taking Bao Shan University as an Example (No.: 2017ZDX061).

School-level research fund Research on Reform and Practice of the Training Mode of Applied Talents in Preschool Education Major -- A Case Study of Bao Shan University (No.: 15BY004).

\section{References}

[1]. Zhu Bingcan, Zhu Tingting, Jiang Fenghua, et al. Exploration of Organization and Implementation of Education Curriculum for Teachers Majoring in Pre-school Education in Colleges -- Based on the Idea of Practice-oriented Curriculum Reform of Teacher Education [J]. China Education Innovation Heral, 2013 (28): 7-8.

[2]. Wang Ying Lan. The Status Quo and Improvement of Practical Curriculum for Preschool Education Major in Undergraduate Level [J]. Studies in Preschool Education, 2012 (11): 53-55.

[3]. Peng Daoyinzhan. Study on Children's Basic Gymnastics Curriculum of Preschool Education Major based on Practical Orientation [J]. The Science Education Article Collects, 2013(20):51-52.

[4]. Li Yunshu. Reform of Praxis-oriented Education Curriculum in Normal Universities -- Based on the Research of UGS Teacher Education Reform [J]. Journal of Educational Development, 2015(3):17-21.

[5]. Xu Jinjin, Hou Jieqiong. A Preliminary Study on the Status of Pre-school Education in the World's Major Countries [J]. Course Education Research, 2016 (18): 228-229.

[6]. Liang Shuangshun. On the Practice of Teacher Education from the Perspective of Teacher Education Curriculum Standards -- A Study Case of Preschool Education Specialty [J]. Journal of Weifang Educational College, 2015 (2): 21-23.

[7]. Wang Zhiqiong, Jin Donghai, Peng Yi, et al. The Construction and Implementation of the Whole Practice Teaching System of Preschool Education Major in Independent Colleges -- Taking Zhixing College of Northwest Normal University as an Example[J]. Journal of Inner Mongolia Normal University (EDUCATION SCIENCE EDITION), 2016,29 (12): 56-59.

[8]. Tang Yan. Guidance and Promotion -- Thoughts on Leading and Promoting the Development of Preschool Education [J]. Journal of Hainan radio \& TV University, 2012, 13 (3): 141-145. 